\title{
Research on Waste Treatment of Scale Farms
}

\author{
Luo Xinrong, Bian Daqing, Shi Jing \\ College of Economic and Management, Tarim University, Alar, Xinjiang 843300
}

Keywords: farm; waste; processing

\begin{abstract}
With the increasing demand for livestock such as chicken and duck cattle and sheep, the birth of scale farms has largely solved the demand of cities for animal products, however, the environmental pollution problem is becoming more and more serious. Nowadays, reducing pollution of large-scale farm waste has become a problem that we must face. Therefore, the author mainly researches on the methods and management methods of large-scale farm waste disposal, and hopes to provide references and suggestions for our country's green aquaculture at the same time in improving the environment pollution in rural areas.
\end{abstract}

\section{Foreword}

With the development of the city, the city has increased the demand for chicken and duck cattle and sheep, and in order to meet the needs of the city, the development of large-scale farms around the city is a very effective response. However, the issue of farm waste that follows is also a problem that we must face. The environmental pollution problems caused by scale farms are also very obvious. If it is not possible to deal effectively with the waste of the farms, it will not only lead to problems in the surrounding environment of farms, but also lead to a decline in the water quality of drinking water, which may threaten the living environment and physical health of rural residents. Therefore, we must implement the change of farm waste disposal method and management mode, and construct green scale culture.

\section{Problems existing in the treatment of scale farm waste}

As far as many large-scale farms in our country are concerned, many more advanced processing technologies are cost-effective in the treatment of livestock and poultry dung, and it is difficult to meet their production requirements for less investment, low cost and good results for the majority of small and medium-sized farms. For some farms which have been set up for livestock and poultry dung, although some reduction of farm pollutant emissions, but from the practical effect, because of technology backwardness processing effect is not obvious, for example, many breeding sites adopted livestock and poultry dung processing technology can not meet the requirements of "farm irrigation water quality standard" and "Livestock and poultry breeding pollutant discharge standard" requirements, for example, some sewage treatment facilities in winter cold Jilin unable to function properly. In short, due to the backwardness of technology, the processing effect of farm waste is largely limited.

As a result of the construction of waste treatment facilities, the waste treatment facilities of many farms are self-financing and self-built, and many farms are often imitated in order to reduce cost inputs, such as the construction of waste treatment facilities, which often exist in the absence of professional design. This is due to the scale of culture, breed type, dirt collection mode and geographical environment, blindly to follow the construction mode of other farms, failed to construct according to the actual situation of the farm, so that the facilities can not play the actual discharge requirements. For example, when a sewage treatment facility is being constructed, it is not possible to discharge the sewer according to the actual conditions of the farm, which can lead to the discharge of sewage and further contaminate the sewage.

Because the management technology of different waste treatment facilities is not the same, and waste management personnel are relatively small, many farms must choose some people who have 
no technical experience to engage in the management of the waste management, without professional training, let these non-economic employees go into the management of waste treatment, once the waste treatment facilities appear to fail, can not be quickly resolved, resulting in the waste disposal facilities cannot function properly. For example, the biogas fermentation facilities in the farms and the construction of the construction unit after the construction of the construction unit, since no professional training will allow the staff to manage, once the problem is to find the construction unit to solve, it is difficult to guarantee the normal operation of biogas fermentation facilities.

Although our country has paid more attention to farm waste in recent years, the government has encouraged farms to construct waste treatment facilities, but after the completion of the waste treatment facilities, the relevant departments are unable to carry out real-time supervision over the handling of waste disposal facilities, resulting in actual analysis of the processing of farm waste, which has led to further regulation and improvement of the treatment of farm waste, and has not played a real environmental protection role.

In fact, farming is not a high-profit industry, the disposal of waste is also a great difficulty for such a low-profit sector, especially as the greater the number of aquaculture, the more pollution it causes, the higher the cost of disposing of waste. In this case, the policy formulation and improvement of farm waste disposal policies shall be required, as to how to reduce pollution of aquaculture, how to ensure the normal operation of the completed fecal sewage treatment facilities, and how to make comprehensive policy plans on how to make comprehensive utilization of livestock and poultry dung, and to ensure that farm waste minimizes the environment.

\section{Countermeasures and suggestions on disposal of scale farms}

At present, for most farms, the use of water-flushing dung, blisters dung, and dry feces are three kinds of excrement methods. However, because of the water rush, the two kinds of fecal dung can produce a large amount of sewage, and the fecal method of the dry cleaning is due to the lack of sewage, not only can save water, reduce the discharge of fecal sewage, it is very suitable for the disposal of fecal waste in the farm.

The so-called rain water diversion refers to the separation of rainwater and sewage, so that the rainwater can be discharged directly into the channel through the rain pipe network, so as to avoid the rainwater being discharged into the river with the sewage. Therefore, it is necessary to drain rainwater drainage from the roof and road to avoid the rainwater entering the sewage ditch. At the same time, it is necessary to do a good job of rainproof and anti-seepage work in the yard, and avoid the contamination of the environment by dumping livestock and poultry manure into wastewater pools and rivers.

The so-called solid-liquid separation is a pretreatment technique of fecal pollutant, mainly through physical or chemical means and equipment, separate the faeces of animals in the farms into solid and liquid two forms, to achieve solid liquid separation of pollutants. Solid-liquid separation technology can reduce COD in fecal pollutants by about $15 \%$, which is very suitable for the waste disposal of fecal waste for farms.

For farms, drinking fountain dripping is also one of the important sources of sewage. In order to avoid dripping into sewage, the first of the farms should regularly check whether the drinking water is in good condition in the farms, and the leakage should be handled in a timely manner; secondly, regularly check the water pressure of the drinking fountain in the farms, avoid the water pressure too high, cause the water leakage of the water cooler; then, regularly check the water scale of the drinking fountain, and the farms should timely conduct water-scale softening treatment for such situations, avoid dripping leakage, and increase the pollution of the farm environment and the increase of sewage.

The waste of farms is mainly composed of nitrogen and phosphorus, and nitrogen mainly comes from the degradation of crude protein and amino acid, which is not digested by digesting animals, but also phosphorus and calcium phosphate, which is not digested in animal feed. For example, in pig-based farms, one fifth of the nitrogen substance in a pig's historical data is excreted through the 
feces, and about half of the nitrogen is excreted through urine. With the progress of science and technology, many farms began to use green feed and feed additives containing low pollution elements, which effectively reduced the concentration of trace elements such as nitrogen and phosphorus in farm waste and played a very good environmental protection.

In recent years, as the environmental pollution problems caused by farm waste have become more and more serious, many laws and regulations on waste disposal have also played a very important role. However, there are some laws and regulations in the management practice of farm waste management, which partly affects the maximum effect of farm waste treatment. Therefore, in order to improve the laws and regulations of waste disposal, local governments should set up a set of laws and regulations suitable for local practice, such as formulating specific policies on saving resources, preventing and controlling pollution and eliminating public hazards, and implementing the various details of the relevant laws and regulations on farm waste disposal, and the disposal of waste disposal policies and farm waste disposal.

In order to reduce the pollution of farm waste in the environment, it is very important to strengthen the management and planning of aquaculture. Therefore, the management and planning of aquaculture should actively adjust the aquaculture industry development policy, in order to gradually reduce the cultivation of farmers, strengthen the supervision and management of large-scale farms, to make scientific and reasonable planning for the site selection of newly-built farms, to avoid pollution in sensitive area environment, to ensure the cultivation scale in the soil can carry the livestock and poultry dung, to strengthen the supervision and management of ultra-large-scale farms, to avoid large-scale farms causing large-scale environmental pollution. Secondly, the policy should encourage and support the use of new technologies for farm waste disposal, give a certain reward and support for the processing of waste disposal, and increase the support for new farms and give support to the implementation of waste disposal, and raise the enthusiasm of farm waste treatment.

Relevant departments should intensify the propaganda work such as broadcasting, television, wall advertising and other propaganda work, on the one hand, to actively publicize relevant laws and regulations, on the other hand, we should actively publicize relevant supportive policies, measures of governance, and the success is typical, so as to realize the importance of farm waste disposal, so that people can form the self-consciousness of environmental protection. In addition, the government should actively publicize the waste treatment technology to the farms, conduct training on farms, let the farms realize the importance of waste treatment, also let the farms have perfect waste disposal techniques and capabilities, ensure that each farm can conscientiously implement waste disposal work.

After years of development, our country farm has made great progress in waste treatment technology, but compared with some developed countries in Europe and the United States, we still need to further research on the technology of farm waste treatment, strengthen the evaluation and research on the existing waste treatment technology, from the technical process, the season processing effect, the basic input and operation cost, etc., to explore suitable different animal species, different scales, different geographical environment, the technical feasibility and economic feasibility of the sewage treatment process and mode.

\section{Concluding remarks}

Environmental protection is not the responsibility of the state, but the responsibility of everyone and every enterprise. Nowadays, environmental pollution caused by farm waste has become a major problem that restricts the sustainable development of breeding industry. The disposal of waste also requires the governments and enterprises to work together to effectively guarantee the effectiveness of waste disposal. 


\section{Acknowledgment}

Foundation project: BINGTUAN university training program, research on the green development path of BINGTUAN economy under the constraints of resources and environment"

\section{References}

[1] Appendix 1, Li Zhi, Yu Haixia, Fu Wynn. Waste treatment of livestock and poultry farm waste disposal measures and countermeasures research. The contemporary animal husbandry. 2015 (12): 45-47.

[2] A brief discussion on the treatment and environmental management of livestock and poultry breeding. Animal Husbandry Veterinary Digest, China (03): 80-80.

[3] Fig. 3 Xiangdong, Huangren, He Zhongwei. Analysis of the status of waste treatment of livestock and poultry farms. Jiangsu Agricultural Sciences, 2014 (01): 302-304.

[4] A Study of the Environment Economic Economic Model Based On Economic Economic Model Based On Economic Economic Model. 2014 (03): 341-344.

[5] A Brief Discussion on the Environmental Problems of Livestock and Livestock Waste and Its Governance Method: The Report of the Friends of the Peasant Association. 2016 (16): 240-241. 